\title{
El Derecho penal del riesgo globalizado. \\ Desafíos para un Derecho penal legítimo \\ y trasnacionalmente efectivo
}

\section{The Globalized Criminal Law}

of Abstract Endangerment.

Challenges for a Legitimate Transnational and Effective Criminal Law System.

\author{
Mario Spangenberg Bolivar* \\ *Universidad Católica del Uruguay \\ guspange@ucu.edu.uy \\ http://dx.doi.org/10.22235/rd.v1i15.1377
}

RESUMEN: La globalización ha provocado un incesante auge de los delitos trasnacionales y una expansión de verdaderas redes criminales multinacionales que exigen, a modo de contrapartida, la creación y el desarrollo de un Derecho penal a la altura de los fenómenos delictivos modernos. El presente trabajo aborda los desafíos que enfrenta el actual Derecho penal para reconfigurarse como trasnacionalmente efectivo en aras de mantener su legitimidad democrática.

Palabras ClaVe: imputación penal, derecho penal de riesgo, derecho penal globalizado, legitimidad democrática, sistema penal internacional. 
ABSTRACr: Globalization has caused a rise of transnational crime and multinational criminal networks, which require, in return, the development of new rules of law. This article deals with the challenges of criminal law to transform itself as transnationally effective, and to maintain its democratic legitimacy.

KEY-WORDS: imputation in criminal law, criminal law of abstract endargement, globalized criminal law, democratic legitimacy, international criminal system.

SUMARIO: I. Introducción. II. Derecho penal del riesgo. 1. La ampliación de las esferas de protección. 2. La transformación de la imputación penal. 3.- Las cuestiones procesales. 4.- La flexibilización del principio de legalidad. 5.- Desafíos para un Derecho penal del riesgo constitucionalmente legítimo. III. Derecho penal de la globalización. 1. Modelo de cooperación entre Estados. 2. Modelo de supranacionalidad. 3. Desafíos para un Derecho penal globalizado. a) La obligatoriedad de las normas internacionales. b) La legitimidad de las normas internacionales. IV. Conclusiones. Bibliografía. 


\section{INTRODUCCIÓN}

Las profundas transformaciones que en las últimas décadas vienen experimentando las sociedades modernas, han provocado -como es notorio- verdaderas reconfiguraciones que atañen no sólo a lo económico, a lo político y a lo social, sino también y con singular impacto, a las diversas áreas del conocimiento teórico y práctico vinculadas a tales aspectos. Y ello, como es obvio, es lo que viene ocurriendo también al interior del Derecho penal.

Por su parte, tales reconfiguraciones son dables de ser observadas desde una perspectiva meramente nacional o interna o también -y ello parece revestir de mayor atractivo y solidez científica- desde una visión inter o supranacional, es decir, más global.

En los hechos, si algún tema, en la bibliografía penal contemporánea, es merecedor de una consideración cercana al consenso, ése es, precisamente, la distancia existente entre el moderno Derecho penal ${ }^{1}$ y su, cada vez más lejano, antecesor modelo clásico. ${ }^{2}$

$\mathrm{Y}$ es que, en efecto, no resulta una tarea sencilla pretender armonizar los actuales fenómenos delictivos, ni las regulaciones penales vigentes o proyectadas, con las coordenadas liberales que marcaron el mundo jurídico penal occidental -al menos- desde la Ilustración,

\footnotetext{
1 Algunos autores utilizan la expresión "Derecho penal del riesgo" o "Derecho penal de la sociedad del riesgo" como sinónimo del Derecho penal moderno, en contraposición al Derecho penal liberal clásico. Entre otros: Cornelius Prittwitz, "Sociedad del riesgo y derecho penal", en Luis Arroyo, Ulfrid Neumann y Adán Nieto (Coord.), Critica y justificación del derecho penal en el cambio de siglo (Cuenca, Universidad Castilla - La Mancha, 2003), 265; Claus Roxin, Derecho Penal. Parte General. Tomo I. (Madrid, Civitas, 1997), 61; José Diez Ripollés, La politica criminal en la encrucijada (Buenos Aires, B de F, 2007), 132 y ss.; y Felix Herzog, "Sociedad del riesgo, derecho penal del riesgo, regulación del riesgo -Perspectivas más allá del Derecho Penal-”, en Luis Zapatero, Ulfrid Neumann y Adán Nieto Crítica y justificación del derecho penal en el cambio de siglo...

Estas expresiones, como es notorio, encuentran cabida en la estrecha vinculación de la moderna regulación jurídico penal con el modelo social postindustrial de la "sociedad de riesgo" descripto por el sociólogo Beck, en Ulrich, Beck, La sociedad del riesgo. Hacia una nueva modernidad (Barcelona, Paidós, 1998). También en Ulrich, Beck, Anthony Giddens y Lash, Scott, Modernización reflexiva. Política, tradición y estética en el orden social moderno (Madrid, Alianza, 2008).

2 Las expresiones Derecho penal moderno y Derecho penal clásico encuentran una precisa exposición en Winfried Hassemer, Persona, mundo y responsabilidad. Bases para una teoría de la imputación en derecho penal (Bogotá, Temis, 1999), 15 y ss. También aborda el punto, aunque refiriendo a modelos mínimos y máximos de sistema penal, Luigi Ferrajoli, Derecho y razón. Teoría del garantismo penal (Madrid, Trotta, 1995), 91 y ss.
} 
en especial, si se toma nota de las singulares aristas y proyecciones internacionales de la cuestión.

A un plano conceptual distinto, claro está, corresponde la discusión en torno a las bondades o defectos de esta evolución, e incluso, a si resulta razonable -o ya es utópicoexigir, dado el actual estado de situación, un retorno sin más al modelo clásico. ${ }^{3}$ Según Schünemann ${ }^{4}$, el Derecho penal se encuentra ante un verdadero callejón sin salida: entre la intransigencia de la Escuela de Frankfurt (abocada a insistir, casi infantilmente, en la vigencia absoluta de los principios clásicos) y la capitulación del Derecho penal del enemigo de Jakobs y buena parte del funcionalismo de Bonn.

Ocurre que, en las últimas décadas, y a un ritmo cada vez más acelerado, conviven en la transformación de la sociedad y en consecuencia, también de la criminalidad y en el propio estado de situación del Derecho penal, dos grandes dimensiones:

Por un lado, el fenómeno de la globalización que, en sus consecuencias técnicas, sociales, económicas y políticas, ha resultado ser un terreno más que propicio para un incesante auge de los delitos trasnacionales y para la génesis y expansión de verdaderas redes criminales multinacionales, y que, indefectiblemente, coloca al Derecho penal ante una muy incómoda encrucijada, pues:

a) o se mantiene encorsetado en la vieja vestidura del Derecho penal clásico, aislado en la estructura de la soberanía nacional estatal e intentando dar respuestas -a modo de golpes al aire- que llegan, mal y tarde, a fenómenos criminales que ya han vuelto a mutar hacia otro rumbo; lo que en definitiva, no supone otra cosa que claudicar del ejercicio del ius puniendi frente a las organizaciones y modalidades criminales más peligrosas y sofisticadas, arriesgando, en consecuencia, no sólo su efectividad sino incluso, su propia legitimidad democrática;

b) o por el contrario, comienza a ensayar nuevos caminos que le permitan estar, mínimamente, a la altura de las circunstancias actuales, procurando convertirse él mismo, en un Derecho penal efectivo trasnacionalmente, a la par de los fenómenos criminales que intenta combatir.

Sobre esta dimensión, y sobre los múltiples problemas y desafíos que allí es dable encontrar, volveré más adelante, en el capítulo 3 de este trabajo.

\footnotetext{
3 Como parece empeńado en continuar reclamando - sin mucho éxito, claro está- un sector no menor de la academia penal.

4 Bernd Schünemann, Consideraciones criticas sobre la situación espiritual de la ciencia jurídico-penal alemana (Bogotá, Universidad del Externado de Colombia, 1998), 13 y 14.
} 
Por ahora, y en el desarrollo del capítulo 2, quiero detenerme en una segunda característica de las sociedades modernas, y por ende también del actual estado de situación del Derecho penal; y es que, además de la universalización de la globalización de los fenómenos delictivos, las sociedades modernas son sociedades basadas en la creación de riesgos y fundamentalmente, de riesgos anónimos.

$\mathrm{Y}$ es, precisamente, en la interacción o concurso entre esos riesgos cada vez mayores y más sofisticados, y la inagotable expansión de las conductas y su anonimato, por fuera de los límites materiales y naturales que durante siglos contuvieron al comportamiento humano y a sus efectos, dentro de un parquet de consecuencias físicas limitado, que se ha forjado el carácter de buena parte del moderno Derecho penal. ${ }^{5}$

La hipótesis que orienta al presente trabajo consiste en señalar-dado el actual estado de situación trasnacional de los fenómenos delictivos- algunos de los desafíos que, en las próximas décadas, habrá de enfrentar el Derecho penal, en cuanto a su eficacia y en consecuencia, también y fundamentalmente, en relación a su propia legitimidad democrática.

\section{DERECHO PENAL DEL RIESGO}

Este Derecho penal del riesgo, como le ha dado en llamar la doctrina alemana -y bajo su impulso, buena parte de la doctrina comparada- se caracteriza, principalmente, por una marcada expansión frente al núcleo clásico, expansión que ha tenido lugar -y presumiblemente lo hará aún con mayor vigor- en múltiples dimensiones. ${ }^{6}$

\footnotetext{
5 Como ha seńalado el sociólogo Beck, en una obra de singular repercusión en el ambiente penal (Beck, Ulrich, La sociedad del riesgo, Barcelona, Paidós, 1998), las sociedades modernas se caracterizan, primero, por la sistemática y creciente producción de riesgos que, en tanto tales, deben administrar: "En la modernidad avanzada, la producción social de riqueza va acompañada sistemáticamente por la producción social de riesgos. Por tanto, los problemas y conflictos de reparto de la sociedad de la carencia son sustituidos por los problemas y conflictos que surgen de la producción, definición y reparto de los riesgos producidos de manera científico - técnica.” Beck, La sociedad, 25 . Y al mismo tiempo, la circunstancia de que esos riesgos, tan característicos de las sociedades actuales, tienen su origen en las actividades humanas, es decir, en los actos u omisiones de otros seres humanos, a diferencia de otras épocas, donde los mayores riesgos tenían su origen -principal, aunque no exclusivamente- en la naturaleza.

$6 \quad$ Especial atención han dedicado a este proceso: Silva, Jesús, La expansión del Derecho penal. Aspectos de la Política criminal en las sociedades postindustriales (Buenos Aires, BdeF, 2011) y el mismo autor, Aproximación al Derecho Penal contemporáneo (Buenos Aires, BdeF, 2012); Albrecht, Peter, El derecho penal en la intervención de la política populista. En La insostenible situación del Derecho penal (Granada, Instituto de Ciencias Criminales de Frankfurt - Área de Derecho Penal de la Universidad Pompeu Fabra, 2000), 471 y ss.; Sánchez, María, El moderno derecho penal y la anticipación de la tutela penal (Valladolid, Secretariado de Publicaciones e Intercambio Científico, Universidad de Valladolid, 1999 ), 11 y ss.; Schünemann, Bernd, El Sistema moderno del Derecho Penal. Cuestiones fundamentales (Buenos Aires, BdeF, 2012); Herzog, Felix, Sociedad del riesgo, derecho penal del riesgo, regulación del riesgo-perspectivas más allá del Derecho Penal-, en: Zapatero, Luis, Neumann, Ulfrid y Nieto, Adán (coordinadores), Crítica y justificación del derecho penal en el cambio de siglo: el análisis crítico de la escuela de Frankfurt (Cuenca, Universidad de Castilla-La Mancha, 2003), 249 y ss.; Prittwitz, Cornelius, Sociedad de riesgo y derecho penal, en: Zapatero, Luis, Neumann, Ulfrid y Nieto, Adán (coordinadores), Crítica
} 


\section{LA AMPLIACIÓN DE LAS ESFERAS DE PROTECCIÓN}

La primera característica de las legislaciones penales vigentes, ${ }^{7}$ es la ampliación de las esferas de protección hacia horizontes antes ignorados por el Derecho penal, como la tutela del ambiente y la creación de delitos de dańo o puesta en peligro del ecosistema, la tutela del mercado y la creación de delitos de competencia desleal, abuso de poder dominante y la protección del orden socioeconómico. Así como también, y muy intensamente, con las múltiples figuras delictivas relacionadas con el lavado de activos y el incumplimiento de deberes formales de prevención de esos riesgos, entre otros variados ejemplos ${ }^{8}$.

En este sentido, el continuo -y cada vez más extendido- requerimiento social de más Derecho penal en los ordenamientos jurídicos modernos, ${ }^{9}$ a modo de conjura global contra todos los males, ha supuesto una modificación sustantiva en la concepción misma del bien jurídico tutelado, pues, como acertadamente señala Hassemer, la protección de bienes jurídicos ha dejado de ser un criterio fundamental de restricción del Derecho penal, para erigirse en el fundamento de la exigencia de más Derecho penal. ${ }^{10}$

Y ello, como es lógico, ha supuesto que la intervención penal no sea vista como de ultima ratio, sino como primer o único remedio jurídico a los males sociales; circunstancia que, naturalmente, socava los cimientos del Derecho penal de una sociedad democrática y en consecuencia, la relación misma entre el Estado y los ciudadanos, pues, como afirma Ferrajoli: “(...) una política penal de tutela de bienes tiene justificación y fiabilidad sólo cuando es subsidiaria de una política extrapenal de protección de los mismos bienes.”11 Principio éste, que ya había sido advertido, dos siglos antes por Montesquieu, al afirmar que:

y justificación del derecho penal en el cambio de siglo: el análisis critico de la escuela de Frankfurt (Cuenca, Universidad de Castilla-La Mancha, 2003), 259 y ss.; Cancio, Manuel, en Jakobs, Gunther y Cancio, Manuel, Derecho penal del enemigo (Buenos Aires, Hammurabi, 2007), 73 y ss.; Diez, José, La política criminal en la encrucijada (Buenos Aires, BdeF, 2007); y Mir, Santiago y Queralt, Joan (Dir.), La seguridad pública ante el Derecho penal (Buenos Aires, BdeF, 2010).

Lo que no significa, obviamente, que, en tanto modelo teórico, tenga, en todos los casos, una exacta y fiel correspondencia con las específicas previsiones normativas nacionales.

8 En la legislación europea incluso, es frecuente encontrar un elenco aún mayor de bienes jurídico-penales que los que pueden hallarse en América Latina. Tal es el caso, por ejemplo, de la protección penal del patrimonio histórico o cultural, prevista en los artículos 321 a 324 del Código Penal español.

$9 \quad$ Según Silva: “...el caso es que, en medida creciente, la seguridad se convierte en una pretensión social a la que se supone que el Estado y, en particular, el Derecho penal deben dar respuesta. ”Silva, Jesús, La expansión, 31. En igual sentido: Albrecht, Peter, El Derecho penal en la intervención, 471.

10 Dice el autor que: "La protección de bienes jurídicos se ha convertido en un criterio positivo para justificar decisiones criminalizadoras, perdiendo el carácter de criterio negativo que tuvo originariamente. Lo que clásicamente se formuló como un concepto crítico para que el legislador se limitara a la protección de bienes jurídicos, se ha convertido ahora en una exigencia para que penalice determinadas conductas, transformándose así completamente de forma subrepticia la función que originariamente se le asignó. ”Hassemer, Persona, 20.

11 Ferrajoli, Derecho y razón, 473. 
"Toda pena que no se derive de la necesidad es tiránica; la ley no es un mero acto de poder, y las cosas indiferentes no le incumben."12

Incluso antes, y más gráficamente, el punto había sido señalado por Santo Tomás de Aquino, al sostener que:

(...) la ley humana está hecha para la masa, en la que la mayor parte son hombres imperfectos en la virtud. Y por eso la ley no prohíbe todos aquellos vicios de los que se abstienen los virtuosos, sino sólo los más graves, aquellos de los que puede abstenerse la mayoría y que, sobre todo, hacen daño a los demás, sin cuya prohibición la sociedad humana no podría subsistir, tales como el homicidio, el robo y cosas semejantes. ${ }^{13}$

Aún más, en la actualidad, la propia descripción del objeto de tutela penal ha abandonado su carácter individual y personal; siendo dable advertir que, los modernos bienes jurídicos se estructuran, con inusual frecuencia, bajo modelos, a la vez, institucionales y universales, como ocurre en el lavado de activos; ${ }^{14}$ y en consecuencia, su descripción, por naturaleza ambigua, legitima o justifica casi cualquier intervención judicial penal, abjurando -de este modo- de su natural función de contención del jus puniendi. ${ }^{15}$

\section{LA TRANSFORMACIÓN DE LA IMPUTACIÓN PENAL}

Las manifestaciones de este proceso, sin embargo, no se circunscriben única, ni mayoritariamente, a la incorporación de un novedoso elenco de bienes jurídico-penales de formato institucional e impersonal, sino que atañen también -y muy especialmente- al modo en que esa intervención penal se lleva a cabo, es decir, a las reglas de imputación penal y al diseño de la estructura típica de las figuras delictivas.

12 Montesquieu, El espiritu de las leyes, (México DF: Porrúa, 1997), XIX, XIV. Sentencia que fuera recogida, también, en su célebre De los delitos y de las penas, por Beccaría, quien, además, se preguntaba: ¿A qué nos viéramos reducidos si se hubiera de prohibir todo aquello que puede inducir a delito? (...) ¿Queréis evitar los delitos? Haced que las leyes sean claras y simples,...”. Beccaria, De los delitos y de las penas (Salamanca: Alianza, 1998), 115. En igual sentido, afirma Hobbes, en Leviatán, que “... una ley que no es necesaria, y carece, por tanto, del verdadero fin de una ley, no es buena." Hobbes, Leviatán o la materia, forma y poder de una república eclesiástica y civil (Buenos Aires: FCE, 2009) XXX y el mismo autor, en De Cive: “...va contra el deber de quienes gobiernan y tienen la autoridad de hacer leyes promulgar más leyes de las que sean necesarias para el bien del magistrado y de sus súbditos.” Hobbes, De Cive (Madrid: Alianza, 2000), XIII.

Summa Theologiae, I-II, q. 96, a.2.

Independientemente de la posición doctrinaria que se adopte respecto a si el objeto de tutela es el orden socio económico o la administración de justicia.

15 En relación a la función crítica o de garantía del bien jurídico, Fernández, Gonzalo, Bien jurídico y sistema del delito (Buenos Aires, BdeF, 2004). 
Y ello, al punto que, para algunos autores, como es el caso de Prittwitz, ${ }^{16}$ es precisamente en este punto, donde se observa, con mayor claridad, el adelantamiento de la frontera de las conductas punibles respecto del límite clásico del derecho penal liberal.

$\mathrm{Y}$ en efecto, esta verdadera anticipación de la intervención penal se deja traslucir en múltiples y variadas formas.

Así, mientras que por un lado, las legislaciones penales modernas se orientan, mayoritariamente, hacia la creación de delitos de peligro, con particular predilección por la modalidad del peligro abstracto ${ }^{17}$ y ello, en desmedro de los clásicos delitos de resultado, también avanzan, indefectiblemente, hacia una mayor punición -y más frecuente- de los delitos tentados, e incluso, de los actos preparatorios sin comienzo de ejecución. Circunstancias que, hasta hace unos años, eran verdaderamente excepcionales en el Derecho penal comparado.

Por su parte, y en forma concurrente, es dable advertir, en la moderna normativa criminal, un excesivo recurso a la utilización de la fórmula de comisión por omisión, para justificar la sanción -desde el Derecho penal-al mero incumplimiento de deberes formales de vigilancia o prevención, a modo de reafirmar la obligatoriedad jurídica de las propias normas; y similar fenómeno expansivo, se pone de manifiesto, al extender el reproche de conductas no directamente intencionales -en no pocas ocasiones, asimilando la respuesta punitiva de las conductas culposas y dolosas- y al ampliar, con excesiva generosidad, las esferas típicas de los grados de coparticipación criminal, lo que supone también, la aplicación de formas, más o menos directas, de expansión del Derecho penal. ${ }^{18}$

\section{LAS CUESTIONES PROCESALES}

Esta moderna tendencia, sin embargo, no permanece contenida en el parquet del Derecho penal sustantivo o en las estructuras dogmáticas que le dan cima, y se adentra también, en aspectos procesales penales, cuyo reflejo más notorio, es la flexibilización de las garantías penales y procesales clásicas y la relativización o distensión de los principios de contención del ius puniendi. ${ }^{19}$

Así, las exigencias derivadas de la presunción de inocencia y del principio de legalidad que, no hace mucho tiempo, constituían una barrera infranqueable frente a las demandas de

\footnotetext{
16 Prittwitz, Cornelius, Sociedad, 261 y ss. En igual sentido: Sánchez, El moderno, 11 y ss.; Silva, La expansión, 4 y 5; y Cancio, Derecho penal del enemigo, 74 y ss. 2013), 33 y 34 .

Jakobs, Gunther, Sociedad, norma y persona en una teoría de un derecho penal funcional (Buenos Aires, Ad Hoc,

18 Silva, La expansión, 45.

19 Silva, La expansión, 4 y 5.
} 
actuación penal, hoy son consideradas meros formalismos que es preciso superar, raudamente, para dar una pronta respuesta a las incesantes demandas sociales de mayor seguridad. ${ }^{20}$

Tal es el caso, por ejemplo, del debilitamiento de la presunción de inocencia, a partir de la aparición de ilícitos como el de enriquecimiento injustificado, o la importancia acordada al incumplimiento o desatención a guías de señales de riesgo de lavado de activos y otras presunciones semejantes, como fundamento del reproche penal en concreto.

Otro tanto acontece, también en relación a la presunción de inocencia, respecto de una de sus manifestaciones más relevantes: la garantía contra la autoincriminación, que parece haber sido hecha a un lado, por la constante utilización de herramientas de investigación como la delación premiada, la figura del testigo protegido, el agente encubierto y los sofisticados mecanismos de interceptación telefónica y seguimiento a distancia, tan dilectos por las legislaciones penales modernas de combate al lavado de activos. ${ }^{21}$

\section{LA FLEXIBILIZACIÓN DEL PRINCIPIO DE LEGALIDAD}

De similar deterioro es objeto, en los últimos años, el principio de legalidad, antes, verdadera regla de oro del Derecho penal. La primera afectación, al nullum crimen nulla pena, ocurre con el permanente dictado de normas, con contenido penal, que no forman parte del Código, al punto que, en buena parte del Derecho comparado, la mayoría de las infracciones penales no están contenidas en el Código, sino en leyes especiales. ${ }^{22}$

A su vez, las remisiones legales -cada vez más frecuentes- a normas de menor jerarquía, como decretos, resoluciones administrativas y circulares del Banco Central, socavan al requisito de estricta legalidad, de un modo incluso aún más grave. ${ }^{23}$

20 Silva señala que: “.... aparecen cada vez con mayor claridad demandas de una ampliación de la protección penal que ponga fin, al menos nominalmente, a la angustia derivada de la inseguridad. Al plantearse esta demanda, ni siquiera importa que sea preciso modificar las garantías clásicas del Estado de Derecho: al contrario, éstas se ven a veces denostadas como demasiado "rígidas" y se abona por su "flexibilización”." Silva, La expansión, 32. En igual sentido, afirma Bauman: "La nuestra es una época de cerraduras patentadas, alarmas antirrobo, cercas de alambre de púas, grupos de vigilancia y personal de seguridad; asimismo de prensa amarillista <de investigación > a la pesca tanto de conspiraciones con las que poblar de fantasmas un espacio público ominosamente vacío como de nuevas causas capaces de generar un < pánico moral> lo suficientemente feroz como para dejar escapar un buen chorro de miedo y odio acumulados.” Bauman, Zygmunt, Modernidad líquida (Buenos Aires, FCE, 2013), 44.

${ }_{21}$ Herramientas de investigación incorporadas, usualmente, al sistema jurídico, en las propias leyes de prevención de lavado de activos o similares. Tal es el caso, por ejemplo, en Uruguay, de la ley 18.494.

22 Llegándose, en el caso uruguayo, al extremo de incorporar normas, con claro contenido penal, en las leyes de presupuesto.

${ }_{23}$ En algunos países, como en Alemania, el contenido típico de la prohibición remite incluso, a manuales técnicos privados, como ocurre en materia de los delitos contra los trabajadores. Ver al respecto: Hortal, Juan, Concreción del riesgo típico en el delito contra la seguridad en el trabajo (art.316 CP). A la vez, un apunte sobre algunos modelos europeos de protección "penal" de la prevención de riesgos laborales. P.84 y ss. En: Mir, Santiago y Corcoy, Mirentxu (Dir.), Protección penal de los derechos de los trabajadores. Seguridad en el trabajo, tráfico ilegal de personas e inmigración clandestina (Buenos Aires, BdeF, 2009). 
Al tiempo que, en no pocas ocasiones, el contenido del principio aparece burlado, bajo una forma ciertamente más velada, mediante la redacción de figuras delictivas con verbos nucleares excesivamente ambiguos, tal y como ocurre, en el lavado de activos, con las expresiones: participar, colaborar, asistir y prestar ayuda.

\section{DESAFíOS PARA UN DERECHO PENAL DEL RIESGO CONSTITUCIONALMENTE LEGÍTIMO}

Así pues, el Derecho penal moderno ha expandido su intervención hacia nuevos sectores, mediante formulaciones típicas amplias o de remisión a normas de inferior jerarquía, con frecuencia sobre la base del peligro al objeto de tutela y de imputaciones omisivas, extendiendo, simultáneamente, el ámbito de reproche, a la realización de actos previos sin comienzo de ejecución típica.

Circunstancias todas ellas, que tienen lugar en un clima de notorio deterioro de las garantías penales y procesales y fundamentalmente, de los clásicos principios de contención al ejercicio del poder penal.

En definitiva, la concepción clásica del Derecho penal, de cuño liberal y garantista, como instrumento de defensa del ciudadano frente al poder sancionatorio del Estado, ha sido desplazada, en las últimas décadas, -y al abrigo de una constante exigencia ciudadana de mayor intervención jurídico penal del Estado- por una innegable expansión de normas de contenido penal e incluso, meramente policial, que permite afirmar, precisamente, que el Derecho penal ya no es lo que era.

Afirmación que, justo es precisarlo, no responde a una melancólica nostalgia, sino a la constatación de la realidad, pues como enseña Zagrebelsky: “Tal vez sea ésta una conclusión que no satisfaga las exigencias de claridad, pureza y coherencia del pensamiento, pero la convivencia humana no es asunto de puro pensamiento." ${ }^{24}$

$\mathrm{Y}$ es que, los tiempos que corren -a estas alturas parece obvio- exigen alejarse, en igual medida, de los fundamentalismos dogmáticos, pero también, del conformismo que esclaviza las razones teóricas a los usos y costumbres de la práctica legislativa de turno.

En ese sentido, el desafío actual y futuro de la ciencia penal en las modernas sociedades del riesgo, y el propio objetivo de la dogmática penal contemporánea no se agota -ni podría hacerlo ya- en la elaboración de una sofisticada teoría del hecho punible, ni en las diversas cuestiones vinculadas a ella, sino también y muy principalmente, en la determinación

$24 \quad$ Zagrebelsky, El derecho, 18. 
científica de las concretas condiciones de legitimidad de un modelo de Derecho penal propio de una democracia constitucional moderna.

En definitiva, en determinar criterios concretos y operativos que permitan establecer límites para distinguir el ejercicio del ius puniendi legítimo de aquél que no lo es.

Es que, si como parece obvio, uno de los rasgos principales de una democracia constitucional moderna, es, precisamente, que el legislador penal no está facultado a diseñar la política criminal a su entero y discrecional arbitrio, sino que, también él, está sujeto a principios y reglas que garantizan la plena vigencia de los derechos fundamentales y cuya observancia o inobservancia habrá de determinar la propia legitimidad de esa política criminal; de ello se sigue la lógica necesidad que el respeto a ésos derechos fundamentales pueda ser, de algún modo, efectivamente contrastado.

Recientemente, y cada vez con mayor amplitud y sofisticación, el Derecho penal constitucional comparado muestra que, en la verificación de la razonabilidad del ejercicio del poder político en materia penal, el principio de proporcionalidad resulta ser una herramienta extremadamente apropiada para esa función.

De allí que buena parte de los desafíos para la ciencia penal en los próximos años, habrán de encontrarse, en los desarrollos del principio de proporcionalidad penal, como instrumento de contralor en la creación y diseño de un Derecho penal constitucionalmente legítimo.

En especial, y ello atañe también y en muy buena medida, al Derecho Constitucional o Político, al alcance y utilización del principio de proporcionalidad penal, en el diseño de la política criminal legislativa, por parte de las Cortes Constitucionales.

\section{1. \\ DERECHO PENAL DE LA GLOBALIZACIÓN}

Ahora bien. Junto a esta dimensión de la expansión del riesgo y del anonimato de sus fuentes, las sociedades modernas se han ido transformando, a un mismo tiempo, en sociedades altamente globalizadas, esto es, universales.

Y ello tampoco es ninguna novedad, pues la vida cotidiana evidencia, a cada paso, que las clásicas fronteras territoriales, carecen de un valor significativo en las interacciones sociales y en consecuencia, tampoco obstaculizan o limitan en modo alguno, sino lo contrario, el desarrollo de los fenómenos criminales. 
Para muestra de este verdadero apogeo de la criminal globalizada, basta con mencionar:

a) las cada vez más complejas redes financieras de delincuencia económica y lavado de activos,

b) el riesgo y la exposición a daños ambientales o biotecnológicos, difíciles de encuadrar en las artificiales categorías de fronteras nacionales, y

c) las poderosas organizaciones criminales dedicadas a la pornografía infantil y a la piratería intelectual e informática,

d) y las variadas modalidades de tráfico, de personas, de órganos, de armas, etc.,

... que son, apenas, algunos ejemplos de la realidad criminal de nuestros días y fundamentalmente, de lo que cabe esperar del fenómeno delictivo de aquí en adelante.

Se trata pues, de nuevas y más complejas formas delictivas, que aprovechan $-y$ vaya si lo hacen- las inagotables posibilidades técnicas y económicas del mundo globalizado, pero no sólo de eso, sino también, de novedosas y desafiantes modalidades especiales de autoría y coparticipación criminal, de la exponencial multiplicación y anonimato de las víctimas y de los victimarios y de una expansión geográfica sin precedentes del iter criminal y de la dispersión y refugio trasnacional de sus ilegales beneficios económicos.

De allí que, si el orden jurídico penal, en tanto ordo -ordenador- aún pretende desempeñar algún rol relevante en las complejas interacciones sociales modernas, no puede permanecer de espaldas a los desafíos de la sociedad globalizada, ni a la dimensión y alcance de sus complejidades y problemas.

Pues como intuían los clásicos -y con lucidez señala ahora Jakobs- el Derecho penal constituye una tarjeta de presentación de la sociedad altamente expresiva, ${ }^{25}$ de allí que quepa exigirle al Derecho penal sus mayores esfuerzos por asumir, con seriedad y convencimiento el desafío de estos nuevos y acuciantes problemas sociales.

En consecuencia, como adelantara, si el Derecho penal moderno pretende estar mínimamente a la altura de las circunstancias, no puede sino procurar convertirse, él también, en un Derecho penal globalizado, esto es, en un Derecho penal efectivo trasnacionalmente.

$\mathrm{Y}$ es precisamente, en la búsqueda de modelos normativos que permitan acercarnos a un Derecho penal efectivo trasnacionalmente, donde la ciencia penal -según los reales

25 Jakobs, Günther, Sociedad, norma y persona en una teoría de un Derecho penal funcional (Buenos Aires, Ad Hoc, 2013), 15 . 
resultados que sea capaz de alcanzar en los próximos años- deberá rendir cuentas sobre su verdadera capacidad de realización y, en definitiva, sobre su propia legitimidad.

Por el momento, en esa búsqueda de un Derecho penal efectivo trasnacionalmente, es posible identificar en el Derecho penal comparado, dos grandes modelos o sistemas, sin perjuicio de la existencia de una gran variedad de formas mixtas o combinadas.

\section{MODELO DE COOPERACIÓN ENTRE ESTADOS}

Por un lado, es cada vez más frecuente hallar sistemas orientados a la cooperación y asistencia entre Estados, a partir de los cuales, las decisiones adoptadas en uno de ellos, resultan aplicables o convocan efectos, en otro Estado.

Este modelo, como es natural, se orienta a dotar de una mayor intensidad y operatividad práctica al esquema clásico de asistencia y colaboración judicial y administrativa, esto es, la cooperación penal internacional.

De allí que, si bien desde una perspectiva meramente teórica, el modelo cooperativo aparenta carecer de originalidad, tampoco es menos cierto que, en no pocas ocasiones, los resultados concretos y prácticos que es capaz de arrojar, no resulten en absoluto desdeñables.

Como es lógico, un modelo jurídico de este tipo, orientado o basado en la cooperación o asistencia entre Estados, exige un fuerte componente de confianza recíproca entre los Estados parte, lo que ciertamente dificulta sus reales posibilidades de éxito por fuera de espacios supraestatales cultural, social e incluso, políticamente homogéneos o afines. De allí que, buena parte de los logros del modelo cooperativo, hayan tenido lugar al interior de la Unión Europea.

Por su parte, y si bien ello ocurre con mayor intensidad en el modelo supranacional, también el sistema de cooperación entre Estados, exige una determinada renuncia o limitación -aunque voluntaria- a la soberanía. Lo que no deja de ser un aspecto de singular importancia, desde el momento que -como enseña Cañardo- es, en las normas penales, donde el atributo de soberanía luce más fuerte.

En los hechos, según el autor:

Esto es así porque son más imperativas que otras variedades de normas. Entendiendo por imperativas las prescripciones acompañadas de un alto grado de coerción incluyendo el uso de la fuerza pública. El Estado soberano es ese repositorio de legítima violencia, y la dimensión coercitiva de un proceso criminal da peso a esta afirmación. Debido a que la coerción organizada es una ca- 
racterística que acompaña al derecho criminal es mucho más fácil de identificar en el ejercicio y en la prerrogativa de la soberanía nacional. ${ }^{26}$

En sentido similar, Sieber ha señalado que: "En el ámbito de los modelos de solución cooperativos cuenta sobre todo la cuestión de en qué medida un Estado que solicita asistencia judicial debe ser apoyado en la persecución de tipos de comportamiento que son impunes en el Estado solicitado." ${ }^{27}$ Para concluir, a partir de la constatación de esa dificultad, que: "Aquí existe una colisión entre la efectiva imposición trasnacional del Derecho penal y la protección del ciudadano contra una distensión extraterritorial excesiva del Derecho extranjero.” Lo que, ciertamente, está lejos de ser un problema menor.

Con seguridad, sea en mérito a estas dificultades que, por el momento, los avances más significativos al interior del modelo de cooperación se hayan conseguido, fundamentalmente, en relación al reconocimiento y aplicación de penas de multa, órdenes de detención europea y exhortos europeos de obtención de pruebas, siempre -claro está- al interior del espacio europeo.

El modelo de cooperación entre Estados, pues, y aunque en forma acotada, ha logrado algunos avances significativos en la trasnacionalidad del Derecho penal, en especial, en lo que hace a la jurisdicción procesal o de aplicación ${ }^{28}$ y, en la mayoría de los casos, vinculado a las normas del soft law penal y no tanto, como sería deseable, respecto al hard law.

\section{MODELO DE SUPRANACIONALIDAD}

Frente al modelo de cooperación entre Estados, se alza otro modelo, verdaderamente más ambicioso en su contenido, y que, en los últimos años, parece concitar un grado cada vez mayor de atención, no sólo en el siempre reducido mundo académico, sino también -y quizás ello sea lo más relevante- en el ámbito de la política internacional, y es el modelo de supranacionalidad.

Este enfoque, de un Derecho penal supranacional, se orienta ya no a lograr una cooperación o asistencia entre los Estados, sino a procurar, desde el inicio, un ámbito de aplicación territorial de las normas penales, significativamente más extenso y en consecuencia, también, más intenso.

26 Cańardo, Hernando V., Cuestiones de Derecho Internacional Penal y la Modificación a la Ley Orgánica Española de Jurisdicción Universal (Buenos Aires, El Dial, 2014).

27 Sieber, Ulrich, Limites del Derecho penal. Fundamentos y desafios del nuevo programa de investigación jurídicopenal en el Instituto Max-Planck de Derecho penal extranjero e internacional. En Revista Penal. No22, España, $2008,131$.

28 Sobre la diferencia entre los aspectos del concepto de jurisdicción, es decir, la "jurisdicción para prescribir o legislar y la jurisdicción para cumplir o aplicar la ley", en extenso, Cañardo, Cuestiones. 
El esquema de supranacionalidad del Derecho penal, que aquí se menciona, si bien no resulta asimilable al concepto ni al funcionamiento de la llamada jurisdicción penal universal, tampoco se encuentra enteramente desligado de ella. En los hechos, es posible aventurar que, gran parte de los desafíos que habrá de enfrentar la construcción -y fundamentalmente, la puesta en práctica- de un espacio penal supranacional, no difieren en demasía de aquellos que, desde hace siglos, vienen socavando el éxito de la jurisdicción universal.

Ocurre, como es obvio, que las dificultades vinculadas al ejercicio de la soberanía nacional, que no son menores en un modelo de cooperación, en un esquema supranacional adquieren una relevancia y gravedad mucho más acentuadas. En palabras de Cañardo, "la mayoría de las cuestiones analizadas se relacionan en forma última con la soberanía estatal, y no podemos escapar a este problema, de ninguna forma." ${ }^{29}$

De allí que, en un modelo supranacional, las cuestiones más arduas tengan que ver, en última instancia, con la propia concepción del poder político, de las posibilidades de delegación del monopolio estatal y en qué condiciones ella es dable de ser sustentada, sin afectar, la propia legitimidad democrática de las prescripciones penales.

En definitiva, y según lo advierte Sieber,

(...) una solución a estos concretos enfoques exige reflexiones básicas sobre teoría del Estado, sobre el principio democrático, sobre el concepto de Derecho penal y sobre la legitimidad del Derecho penal y el poder directivo jurídico-penal. [Pues, sólo] desde un fundamento de este tipo puede desarrollarse una metanorma que establezca también para casos de colisión qué presupuestos democráticos, del Estado de Derecho y de Derechos Humanos, debe cumplir una norma internacional (creadora o determinadora de Derecho Penal) y cuando debe tener prioridad respecto a determinados derechos de protección nacionales o regionales. ${ }^{30}$

Ahora bien. La efectiva vigencia de un modelo penal de supranacionalidad exige, además de una clara voluntad política de renuncia a espacios de soberanía -en zonas donde esta parece exigir mayor firmeza-, de un arduo y sofisticado trabajo de armonización del Derecho penal, en sus aspectos sustantivos y procesales que, como es lógico advertir, tampoco resulta una tarea sencilla.

Sin esa asimilación o armonización del Derecho sustantivo y procesal, el modelo de supranacionalidad dirigido a quitar los espacios de impunidad de la moderna criminalidad globalizada, corre el riesgo de contentarse con una mera lógica simbólica ante la opinión pú-

\footnotetext{
Cañardo, Cuestiones.

Sieber, Ulrich, Limites.
} 
blica y, lo que es aún más grave, de incrementarlos a partir de la confusión jurídica provocada por la compleja yuxtaposición de normas y jurisdicciones competentes.

En esa medida pues, los avances que se pretendan realizar en la construcción de espacios de supranacionalidad penal, no deberían pasar por alto este riesgo.

\section{DESAFÍOS PARA UN DERECHO PENAL GLOBALIZADO}

La enunciación de estas dificultades permite apreciar el extenso elenco de cuestiones verdaderamente complejas- que yacen al interior del proceso de búsqueda de un Derecho penal efectivo trasnacionalmente, ya sea, a partir de la acentuación del modelo de cooperación entre Estados o, en lo que es una aventura más ambiciosa, mediante la creación de espacios de supranacionalidad penal. Sin embargo, la existencia de estos obstáculos, que ciertamente no son menores, en poco atempera la necesidad -ni la urgencia- de que el Derecho penal se vuelva, al menos, mínimamente operativo trasnacionalmente.

\section{a) La obligatoriedad de las normas internacionales}

A ello debe agregarse, como dificultad intrínseca a las normas internacionales, la circunstancia que, a diferencia de lo que ocurre con los derechos nacionales o internos de los países, el Derecho internacional público, ofrece una singular problemática en relación a su efectivo cumplimiento por parte de los sujetos a los que está principalmente dirigido, esto es, a los Estados.

Y es así que el estudio del Derecho internacional público -y en consecuencia, también del Derecho internacional penal- no puede soslayar el peso específico y la real capacidad de poder de los sujetos a los que está dirigido.

De allí que no luzca ocioso, en la propia construcción de espacios de supranacionalidad penal, el interrogarse si efectivamente las normas internacionales que le dan cima, resultan normas jurídicas coercitivas (en el sentido del derecho común) o si por el contrario, se trata de meras reglas de comportamiento sustentadas en mutuas promesas estatales de actuación, pero a las cuales los Estados -fácticamente- no quedan sujetos; o al menos, no en el mismo sentido que los particulares frente a sus respectivos derechos internos.

En esa dirección, el hecho de que el Derecho internacional público no sea Derecho puesto sino acordado, complejiza aún más, la ya ardua tarea de concreción de un Derecho penal supranacional. Más aún, si se advierten las falencias históricas en el grado de cumplimiento internacional de tales compromisos. 


\section{b) La legitimidad de las normas internacionales}

En este sentido, una visión realista de las normas internacionales, o si se quiere, menos ingenua de las reglas jurídicas internacionales, no puede circunscribirse a su mero análisis exegético, sino a contrastar sus condiciones de legitimidad; esto es, no sólo al origen formal o a la fuente que le ha dado vida, sino también y principalmente, a su aptitud de ser percibida por los propios Estados como obligatoria. ${ }^{31}$

La legitimidad de las normas internacionales, según la doctrina más relevante, como cualidad demostrativa de su real capacidad de cumplimiento y está conformada por diversos aspectos, tales como el pedigreé, la adhesión, la coherencia y la determinación.

En consecuencia, la mayor o menor legitimidad de una norma de Derecho internacional alienta -o disminuye- sus posibilidades reales de cumplimiento por parte de los sujetos a los que está dirigida; por ello, un Derecho comprometido con la realidad, no debería desatender tampoco este aspecto.

En ese sentido, según expresa Thomas: “...the concept of legitimacy can prove illuminating for international law scholarship and practice. It does not require lawyers to abandon the tools of their trade, but rather calls for reflection on how such tools are to be used." 32

En mérito a ello, parece necesario -como ha propugnado Cañardo- que exista, en aras de facilitar un Derecho penal efectivo trasnacionalmente, "un renacimiento del interés que toda la comunidad tiene en la observancia o cumplimiento de la ley (...) Aceptar esto requiere cambiar las concepciones del poder soberano y en la actualidad, es esto más difícil aún que después de la Segunda Guerra Mundial, a pesar de la cantidad de Instrumentos y Tribunales sobre la materia". ${ }^{33}$

Pues, en definitiva, como señala el mismo autor, "la existencia de la jurisdicción universal, así como de las Cortes; ya sean ad hoc, Internacionales, o hibridas son solo una solución parcial. Es necesaria una transformación para lograr resultados concretos requiriéndose

\footnotetext{
31 Acerca de la legitimidad de las normas internacionales, como cualidad demostrativa de su real capacidad de cumplimiento y los diversos aspectos que la integran, tales como el pedigreé, la adhesión, la coherencia y la determinación: Georgiev, Dencho, Politics or Rule of Law: Deconstruction and Legitimacy in International Law, European Journal of International Law (EJIL), 1993, 1-14; Besson, Samantha, The Authority of International Law - Lifting the State Veil, Sydney Law Review, Vol.31, 2009; Franck, Thomas M., Legitimacy in the International System, The American Journal of International Law, Vol.82, 1988; Bodansky, Daniel, Legitimacy in International Law and International Relations, International Law/International Relations: A Stocktaking (Jeffrey Dunoff \& Mark Pollack eds. Cambridge University Press, 2012) 321-341; Thomas, C.A., The Concept of Legitimacy and International Law, LSE, Law, Society and Economic Working Papers, 12/2013.

32 Thomas, C.A., The Concept of Legitimacy and International Law, LSE, Law, Society and Economic Working Papers, 12/2013, p.5.

33 Cańardo, Cuestiones.
} 
una gradual reorientación de las elites nacionales hacia la aceptación imparcial de standards legales comunitarios efectivos." 34

En puridad, se observa una preeminencia de la importancia de aspectos más relacionados con la dimensión política que los meramente jurídicos.

\section{IV. \\ CONCLUSIONES}

En conclusión, el verdadero desafío de la ciencia penal de nuestros días, no reside en la práctica sofisticada de una crítica exegética a las normativas vigentes o proyectadas, por más inteligente que esta sea, pues ello, en el actual estado de situación, es una manera, quizás elegante pero de seguro inútil, de abonar un status quo, que en una democracia constitucional moderna, ya no puede tener cabida.

Las transformaciones sociales que han tenido lugar en las últimas décadas, exigen la creación y el desarrollo de un Derecho penal del riesgo y globalizado, que esté a la altura de los desafíos cotidianos, pues de ello depende, en buena medida, la propia legitimidad democrática del sistema penal nacional e internacional.

En otras palabras, el Derecho penal moderno, propio de una democracia constitucional, no es aquél que se contenta y satisface con atrapar, una y otra vez, a los perdedores de siempre -a los que, claro que no debe dejar de atrapar- sino también, y fundamentalmente, el que intenta estar a la altura de los desafíos modernos, que no son otros, que los propios de la sociedad del riesgo y globalizada en que vivimos y en la que, el Derecho penal está llamado a asegurar la convivencia.

Hace ya algunos años, Betrand de Jouvenel, sentenció: El Derecho ha perdido su alma y se ha convertido en una jungla.

Pues bien. El desafío de la ciencia jurídica, y del Derecho penal internacional, en los próximos ańos, no es otro que ensayar caminos para desandar esta jungla y devolverle el alma al Derecho.

Para citar este artículo: Spangenberg, Mario, El Derecho penal del riesgo globalizado. Desafíos para un Derecho penal legítimo y trasnacionalmente efectivo. Revista de Derecho, 15 (I, 2017), ISSN 1510-3714, ISSN On line 2393-6193: 257-276.

34 Cañardo, Cuestiones. 


\section{BIBLIOGRAFÍA}

Albrecht, Peter, El derecho penal en la intervención de la politica populista. En La insostenible situación del Derecho penal (Granada, Instituto de Ciencias Criminales de Frankfurt Área de Derecho Penal de la Universidad Pompeu Fabra, 2000): 471-487.

Bauman, Zygmunt, Modernidad líquida (Buenos Aires, Fondo de Cultura Económica, 2013).

Beccaria, Cesare, De los delitos y de las penas (Salamanca, Alianza, 1998).

Beck, Ulrich, Giddens, Anthony y Lash, Scott, Modernización reflexiva. Política, tradición y estética en el orden social moderno (Madrid, Alianza, 2008).

Beck, Ulrich, La sociedad del riesgo. Hacia una nueva modernidad (Barcelona, Paidós, 1998).

Besson, Samantha, "The Authority of International Law - Lifting the State Veil", Sydney Law Review Vol. 31(2009): 343-380.

Bodansky, Daniel, Legitimacy in International Law and International Relations, International Law/International Relations: A Stocktaking (Jeffrey Dunoff \& Mark Pollack eds. Cambridge University Press, 2012) 321-341.

Cancio, Manuel, Derecho penal del enemigo, Gunther Jakobs - Manuel Cancio (Buenos Aires, Hammurabi, 2007).

Cañardo, Hernando V., "Cuestiones de Derecho Internacional Penal y la Modificación a la Ley Orgánica Española de Jurisdicción Universal”, El Dial (Buenos Aires, 2014): http://www.eldial.com/nuevo/tcd-detalle.asp?base=50\&vengode=suple\&fecha_publi car $=27 / 04 / 2017 \&$ suple $=$ Constitucional $\& i d=7732$

Diez, José, La política criminal en la encrucijada (Buenos Aires, B de F, 2007).

Fernández, Gonzalo, Bien jurídico y sistema del delito (Buenos Aires, BdeF, 2004).

Ferrajoli, Luigi, Derecho y razón. Teoría del garantismo penal (Madrid, Trotta, 1995).

Franck, Thomas M., "Legitimacy in the International System", The American Journal of International Law Vol.82, No4 (1988): 705-759.

Georgiev, Dencho, "Politics or Rule of Law: Deconstruction and Legitimacy in International Law”, European Journal of International Law (EJIL) (1993): 1-14.

Hassemer, Winfried, Persona, mundo y responsabilidad. Bases para una teoría de la imputación en derecho penal (Bogotá, Temis, 1999).

Herzog, Felix, "Sociedad del riesgo, derecho penal del riesgo, regulación del riesgo Perspectivas más allá del Derecho Penal-”, en Luis Zapatero, Ulfrid Neumann y Adán Nieto, Crítica y justificación del derecho penal en el cambio de siglo (Cuenca, Universidad Castilla - La Mancha, 2003): 249-258. 
Hobbes, Thomas, De Cive (Madrid, Alianza, 2000).

Hobbes, Thomas, Leviatán o la materia, forma y poder de una república eclesiástica y civil (Buenos Aires, FCE, 2009).

Jakobs, Gunther, Sociedad, norma y persona en una teoria de un derecho penal funcional (Buenos Aires, Ad Hoc, 2013).

Jouvenel, Bertrand de, Sobre el poder. Historia natural de su crecimiento (Madrid, Unión, 1998).

Mir, Santiago y Corcoy, Mirentxu (Dir.), Protección penal de los derechos de los trabajadores. Seguridad en el trabajo, tráfico ilegal de personas e inmigración clandestina (Buenos Aires, BdeF, 2009).

Mir, Santiago y Queralt, Joan (Dir.), La seguridad pública ante el Derecho penal (Buenos Aires, BdeF, 2010).

Montesquieu, El espíritu de las leyes (México DF, Porrúa, 1997).

Prittwitz, Cornelius, “Sociedad del riesgo y derecho penal”, en Luis Arroyo, Ulfrid Neumann y Adán Nieto (Coord.), Critica y justificación del derecho penal en el cambio de siglo (Cuenca, Universidad Castilla - La Mancha, 2003): 259-287.

Roxin, Claus, Derecho Penal. Parte General. Tomo I (Madrid, Civitas, 1997).

Sánchez, María, El moderno derecho penal y la anticipación de la tutela penal (Valladolid, Secretariado de Publicaciones e Intercambio Científico, Universidad de Valladolid, 1999).

Schünemann, Bernd, Consideraciones criticas sobre la situación espiritual de la ciencia jurídicopenal alemana (Bogotá, Universidad del Externado de Colombia, 1998).

Schünemann, Bernd, El Sistema moderno del Derecho Penal. Cuestiones fundamentales (Buenos Aires, BdeF, 2012).

Sieber, Ulrich, "Límites del Derecho penal. Fundamentos y desafíos del nuevo programa de investigación jurídico-penal en el Instituto Max-Planck de Derecho penal extranjero e internacional", Revista Penal No22 (2008), España: 125-159.

Silva, Jesús, Aproximación al Derecho Penal contemporáneo (Buenos Aires, BdeF, 2012).

Silva, Jesús, La expansión del Derecho penal. Aspectos de la Politica criminal en las sociedades postindustriales (Buenos Aires, BdeF, 2011).

Thomas, C.A., "The Concept of Legitimacy and International Law", LSE, Law, Society and Economic Working Papers, 12/2013. https://www.lse.ac.uk/collections/law/wps/ WPS2013-12_Thomas.pdf

Zagrebelsky, Gustavo, El derecho dúctil. Ley, derechos, justicia (Madrid, Trotta, 2011) 